\title{
Article \\ Photofungizides Based on Curcumin and Derivates Thereof against Candida albicans and Aspergillus niger
}

\author{
Barbara Schamberger ${ }^{1,2}$ and Kristjan Plaetzer ${ }^{1, *}$ \\ 1 Laboratory of Photodynamic Inactivation of Microorganisms, Department of Biosciences, \\ Paris Lodron University of Salzburg, 5020 Salzburg, Austria; barbara.schamberger@plus.ac.at \\ 2 Morphophysics Group, Department of Chemistry and Physics of Materials, \\ Paris Lodron University of Salzburg, 5020 Salzburg, Austria \\ * Correspondence: kristjan.plaetzer@plus.ac.at; Tel.: +43-662-8044-5706; Fax: +43-662-8044-150
}

Citation: Schamberger, B.; Plaetzer,

K. Photofungizides Based on

Curcumin and Derivates Thereof against Candida albicans and Aspergillus niger. Antibiotics 2021, 10, 1315. https://doi.org/10.3390/ antibiotics10111315

Academic Editor: Andrew Abell

Received: 1 October 2021

Accepted: 20 October 2021

Published: 28 October 2021

Publisher's Note: MDPI stays neutral with regard to jurisdictional claims in published maps and institutional affiliations.

Copyright: (C) 2021 by the authors. Licensee MDPI, Basel, Switzerland. This article is an open access article distributed under the terms and conditions of the Creative Commons Attribution (CC BY) license (https:// creativecommons.org/licenses/by/ $4.0 /)$.

\begin{abstract}
Fungal infections in humans, contamination of food and structural damage to buildings by fungi are associated with high costs for the general public. In addition, the increase in antifungal resistance towards conventional treatment raises the demand for new fungicidal methods. Here, we present the antifungal use of Photodynamic Inactivation (PDI) based on the natural photosensitizer curcumin and a water-soluble positively charged derivative thereof (SA-CUR 12a) against two different model organisms; Candida albicans grown in a liquid culture and photo treated with a $435 \mathrm{~nm}$ LED light followed by counting of the colony-forming units and photoinactivation of tissuelike hyphal spheres of Aspergillus niger (diameter $\sim 5 \mathrm{~mm}$ ) with subsequent monitoring of colony growth. Curcumin $(50 \mu \mathrm{M}$, no incubation period, i.p.) supplemented with $10 \%$ or $0.5 \%$ DMSO as well as SA-CUR 12a (50 $\mu \mathrm{M}$ no i.p or 5 min i.p.) triggered a photoantifungal effect of $>4 \log$ units towards C. albicans. At $100 \mu \mathrm{M}$, SA-CUR 12a (0 min or 5 min i.p.) achieved a reduction of $>6$ log units. Colonies of $A$. niger shrunk significantly during PDI treatment. Photoinactivation with $50 \mu \mathrm{M}$ or $100 \mu \mathrm{M}$ curcumin (+0.5\% DMSO) resulted in complete growth inhibition. PDI using 20, 50 or $100 \mu \mathrm{M}$ SA-CUR 12a (with or without 10\% DMSO) also showed a significant reduction in colony area compared to the control after $48 \mathrm{~h}$, although less pronounced compared to curcumin. In summary, PDI using curcumin or SA-CUR 12a against C. albicans or A. niger is a promising alternative to currently used fungicides, with the advantage of being very unlikely to induce resistance.
\end{abstract}

Keywords: photodynamic inactivation; photosensitizer; antifungal; curcumin; Candida albicans; Aspergillus niger

\section{Introduction}

From the kingdom of fungi, about 600 species are known to be human pathogens, that can be potentially harmful to immunocompromised people (e.g., Candida spp. or Aspergillus spp.) [1]. As the number of immuno-deficient people increases due to the rising number of patients undergoing cancer therapy, organ recipients or people treated for human immunodeficiency virus, the risk of contracting a fungal infection also increases [2-4]. In addition, an increase in antimicrobial resistance is observed in recent years [5]. Fungi in the form of mold in buildings cause high costs as well as an increased health risk for the occupants [6]. Therefore, new antifungal agents are needed to counter the increasing number of fungal infections and the increasing antifungal resistance against conventional agents [5].

Photodynamic Inactivation (PDI), also known as Antimicrobial Photodynamic Therapy, is a method that was shown to be highly effective against bacteria [7-12]. PDI uses a photoactive substance, or photosensitizer (PS), which, together with oxygen and excitation by light of an appropriate wavelength, generates reactive oxygen species (ROS) [13]. Unlike antibiotics, PDI is not linked to a specific target in the organism, which is why the development of resistance to PDI is unlikely but must still be considered [14,15]. Two 
different model organisms were selected for the investigation of the potential antifungal effect of PDI: Candida albicans (C. albicans) and Aspergillus niger (A. niger).

Candida albicans is a yeast-like fungus that is harmless in most cases and is found in the oral cavity of over $75 \%$ of the population. Immunocompromised people can suffer from candidiasis in the oral cavity and up to $75 \%$ of women report having had a vaginal infection with Candida spp. at least once in their lifetime. Although these very common superficial infections are not life-threatening, Candida spp. can also lead to systemic infection, where the mortality rate is very high [1]. Antifungal resistance is an increasing problem with Candida. About $7 \%$ of all Candida blood samples tested at the Centers for Disease Control (CDC) are resistant to the antifungal drug fluconazole [16]. Very special concern is rising over Candida auris, which is still rare but a growing threat. Resistance rates for C. auris are much higher than for other Candida species, with about $90 \%$ of U.S. C. auris isolates being resistant to fluconazole, and one-third resistant to amphotericin B [17].

A. niger is a filamentous fungus that can develop conidiophores with black spores [18] and is among other fungal species causing mold growth. Dampness and mold growth in a high humidity environment caused by leaks, inadequate ventilation or extreme natural events (e.g., floods) lead to an increase in respiratory diseases such as asthma and therefore have a major impact on health care costs [6]. In immunocompromised patients Aspergillus spp. can lead to Aspergillus infections, which can even be life-threatening in case of severe septic infections [19]. The shift to energy-efficient housing using air-tight constructions also leads to more favorable conditions for mold growth [20]. It is estimated that people spend about $90 \%$ of their time indoors, so the impact of poor housing conditions, such as those caused by mold, on occupants' health is very high [21]. The most effective step towards mold-free homes is to eliminate the source of moisture in a building and remove materials that are already contaminated. Additionally, biocides such as chlorine bleach might be used, but unfortunately, biocides are also harmful to humans [22]. In the CDC report "Antibiotic resistance threats in the United States 2019", Aspergillus fumigatus is placed on the watch list because of the rise in azole-resistant infections [23].

In PDI a wide spectrum of PSs is known that have already shown high efficiency against bacteria or fungi. However, the use of natural substances such as curcumin, which is classified as a food additive (E100), appears to be a good choice for mild, ecofriendly and biocompatible photoangifungal treatment, as it forms ROS in an appropriate environment [24,25]. Curcumin was shown to be effective against bacteria, e.g., Staphylococcus aureus [26] or fungi, e.g., A. niger [27] or C. albicans [28]. Due to its low solubility in water, curcumin is often dissolved in a solubility enhancer, e.g., $10 \%$ dimethyl sulfoxide (DMSO) [26,28] or propylene glycol [27] and also used as formulations with solubility enhancers [24]. Alternatively, water-soluble curcumin derivates can be used [29-31].

In this study, we introduce SA-CUR 12a, a new curcumin-based cationic PS for antifungal treatment and compare it to natural curcumin, to demonstrate the potential of PDI as an alternative to conventional fungicides. The impact of DMSO on curcuminbased antifungal PDI is determined by using two different concentrations of this solubility enhancer $(0.5 \%$ and $10 \%)$. In the study, two model systems with fundamental distinct growth behavior are used: the yeast-like fungus C. albicans, which is of clinical relevance, and the filamentous $A$. niger having environmental importance.

\section{Results}

\subsection{PDI against Candida albicans with Curcumin or SA-CUR $12 a$}

To determine the effect of the DMSO concentration, the natural PS curcumin with $0.5 \%$ or $10 \%$ DMSO was used against the pathogenic yeast C. albicans in the initial experiments. This solubility enhancer does not have a toxic effect: as shown in Figure 1, the mean CFU of the individual control samples (C-/ - light only, PS only) are in the same order of magnitude (CFU ranging from 1.5-5 $\left.\times 10^{6}\right)$. 


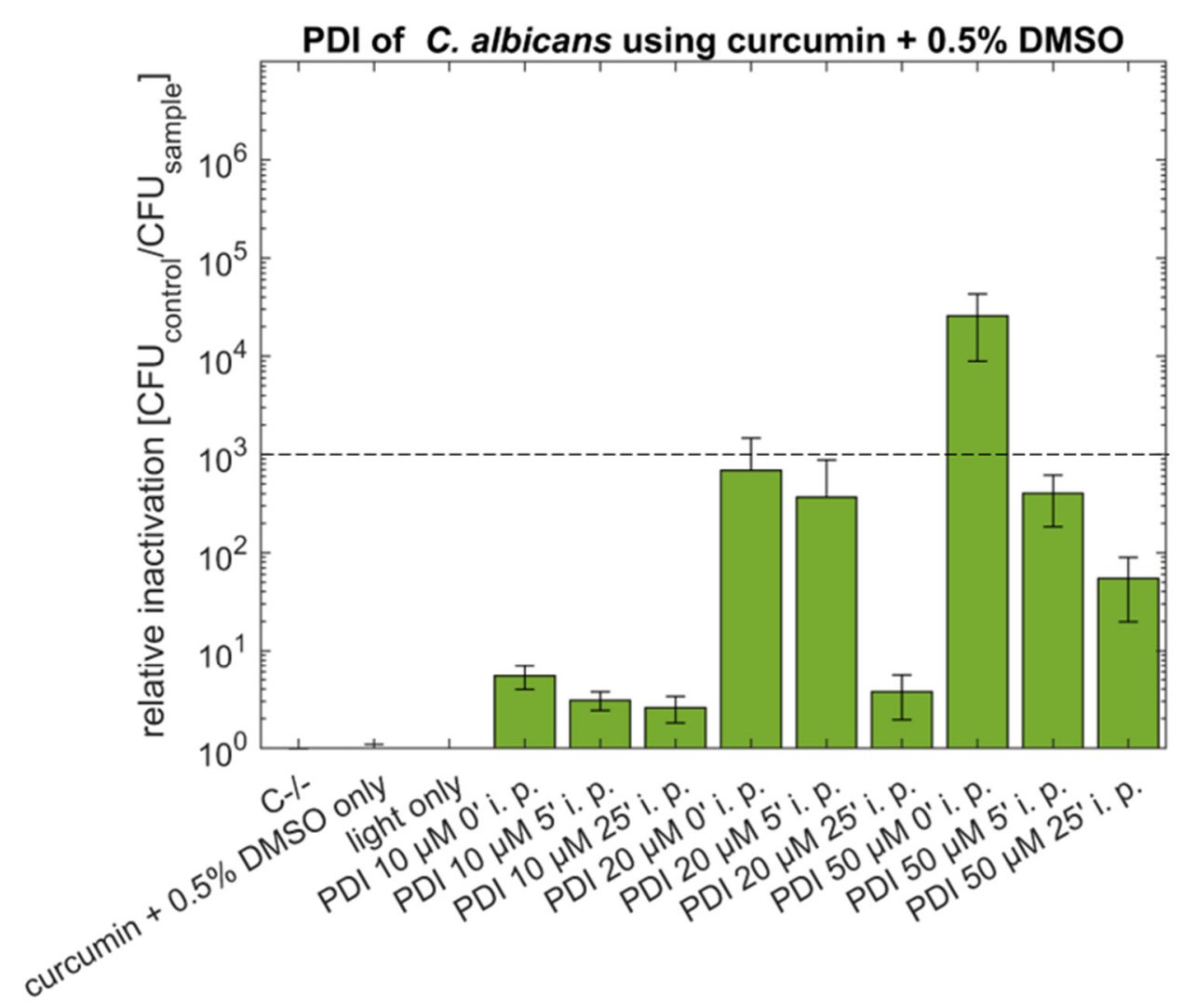

Figure 1. Phototoxicity of curcumin $(10 \mu \mathrm{M}, 20 \mu \mathrm{M}$ or $50 \mu \mathrm{M})+0.5 \%$ DMSO against C. albicans using incubation periods (i.p.) of 0,5 or $25 \mathrm{~min}$. Illumination was performed by using an LED array $\left(15.8 \mathrm{~J} \mathrm{~cm}^{-2} / 435 \mathrm{~nm}\right)$. The plot shows the mean and the standard deviation of the relative inactivation according to $\mathrm{C}-/-(n$ (number of biological replicas $)=3)$. The dotted line indicates a $3 \log$ reduction.

Curcumin dissolved with $0.5 \%$ DMSO showed an antimicrobial effect (reduction of $3 \log$ ) of $2.6 \times 10^{4}$ only in the concentration $50 \mu \mathrm{M}$ without incubation period (i. p.) before illumination. Using a five-minute incubation with the PS before illumination resulted in a decrease in relative inactivation (rel. inactivation $4.0 \times 10^{2}$ ), which was even more pronounced (rel. inactivation $5.5 \times 10^{1}$ ), if the incubation period was extended to $25 \mathrm{~min}$.

After increasing the concentration of supplemented DMSO to 10\% (Figure 2) the antimycotic effect of $50 \mu \mathrm{M}$ curcumin and no incubation before illumination was in the same order of magnitude (rel. inactivation $4.7 \times 10^{4}$ ) as for the lower concentration of DMSO. The effect of the treatments with $50 \mu \mathrm{M}$ curcumin and incubation times of $5 \mathrm{~min}$ (rel. inactivation $1.8 \times 10^{4}$ ) or $25 \mathrm{~min}$ (rel. inactivation $4.3 \times 10^{3}$ ) lead to lower efficiency, but the effect still remains above $3 \log$. Lower concentrations $(5,10$ and $20 \mu \mathrm{M})$ of curcumin with $10 \%$ DMSO induced no antimicrobial effect.

Photodynamic Inactivation based on the water-soluble cationic SA-CUR 12a at concentrations of $50 \mu \mathrm{M}$ without incubation induced an antimycotic effect $\left(3.3 \times 10^{4}\right)$ comparable to $50 \mu \mathrm{M}$ curcumin without incubation. Increasing the incubation time (i.p. $5 \mathrm{~min}$ ) slightly increased the effect to $9.5 \times 10^{4}$. A $25 \mathrm{~min}$ incubation showed no improvement but led to a drop in efficiency below the $3 \log$ criteria to a relative inactivation of $7.5 \times 10^{2}$. Increasing the concentration of SA-CUR 12a to $100 \mu \mathrm{M}$ and incubation for 5 or $25 \mathrm{~min}$ prior to illumination resulted in a pronounced decimation of viable $C$. albicans of at least $1.6 \times 10^{6}$, which was at the detection limit (Figure 3). 


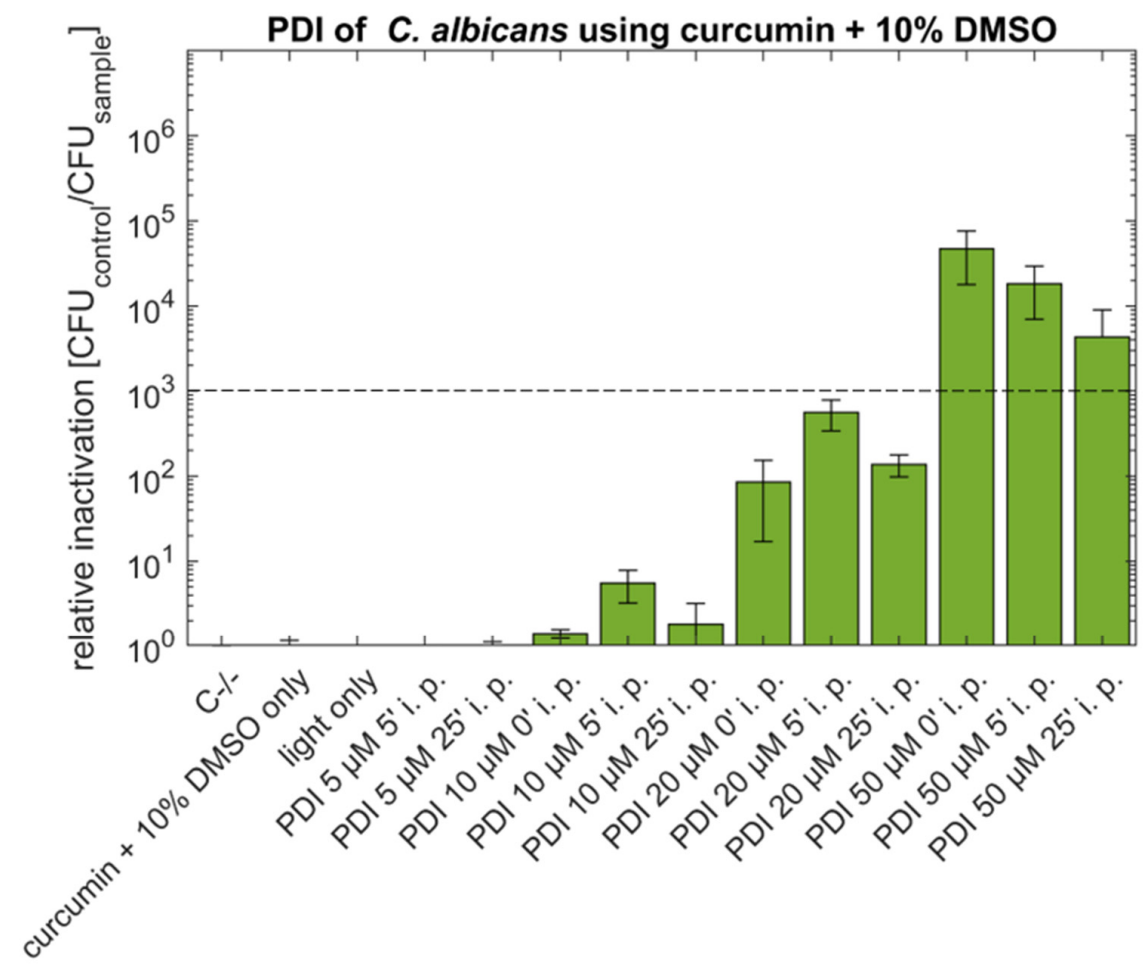

Figure 2. Phototoxicity of curcumin $(5 \mu \mathrm{M}, 10 \mu \mathrm{M}, 20 \mu \mathrm{M}$ or $50 \mu \mathrm{M})+10 \%$ DMSO against C. albicans using incubation periods (i.p.) of 0,5 or $25 \mathrm{~min}$. Illumination was performed by using an LED array $\left(15.8 \mathrm{~J} \mathrm{~cm}^{-2} / 435 \mathrm{~nm}\right)$. The plot shows the mean and the standard deviation of the relative inactivation according to $\mathrm{C}-/-(n=3)$. The dotted line indicates a $3 \log$ reduction.

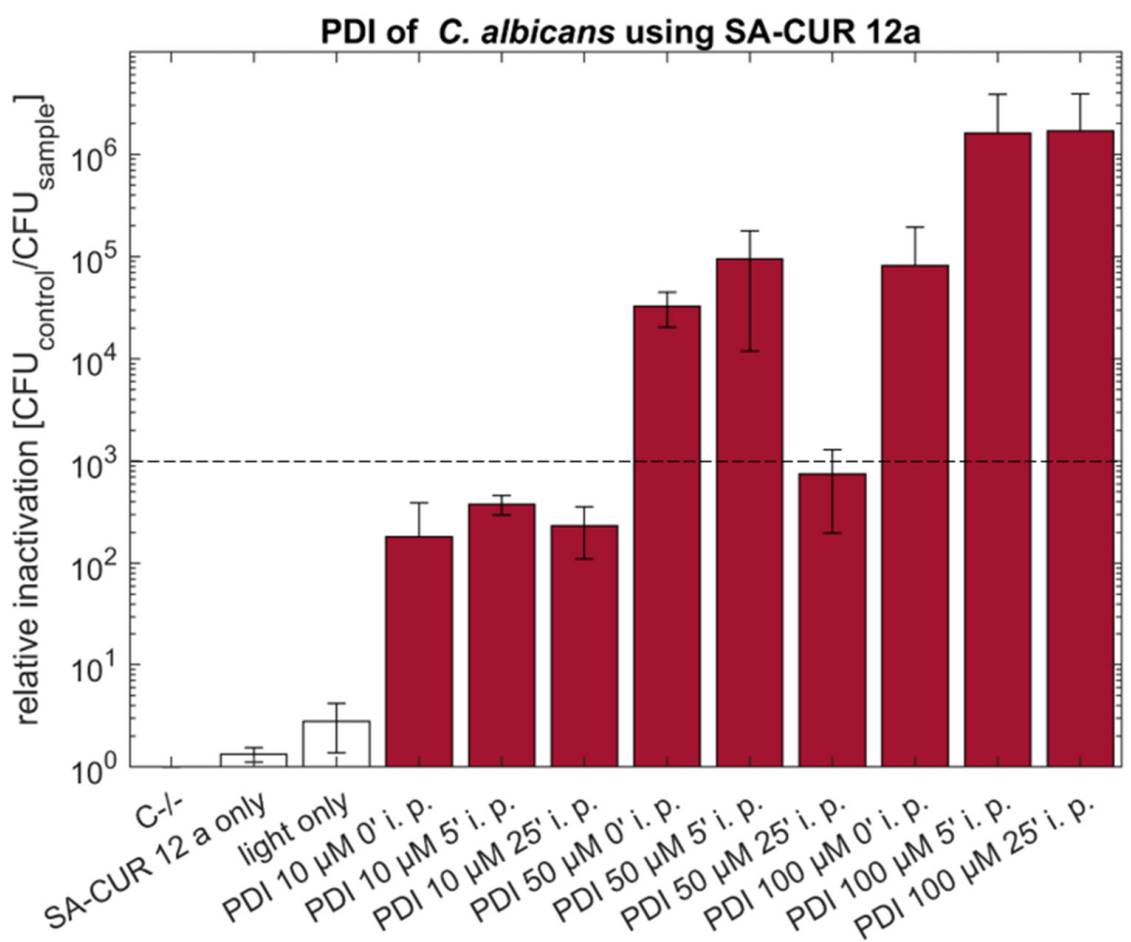

Figure 3. Phototoxicity of SA-CUR $12 \mathrm{a}(10 \mu \mathrm{M}, 50 \mu \mathrm{M}$ or $100 \mu \mathrm{M})$ against $C$. albicans using incubation periods (i.p.) of 0,5 or $25 \mathrm{~min}$. Illumination was performed by using an LED array $\left(15.8 \mathrm{~J} \mathrm{~cm} \mathrm{~cm}^{-2} / 435 \mathrm{~nm}\right)$. The plot shows the mean and the standard deviation of the relative inactivation according to $\mathrm{C}-/-$ $(n=3)$. The dotted line indicates a $3 \log$ reduction. 


\subsection{PDI against Aspergillus niger with Curcumin or SA-CUR $12 a$}

To determine whether PDI treatment leads to a loss of the cell mass immediately after illumination the colony areas of the A. niger mycelial patches were measured before and directly after illumination. Figure 4 displays the diameters of mycelial patches (i.e., colony areas) of $A$. niger photo treated with PS as well as the control groups (C-/-, light only, PS only) before and after illumination. A significant decrease in patch size is seen post-treatment. The list of samples included in each group can be found in the Appendix A.

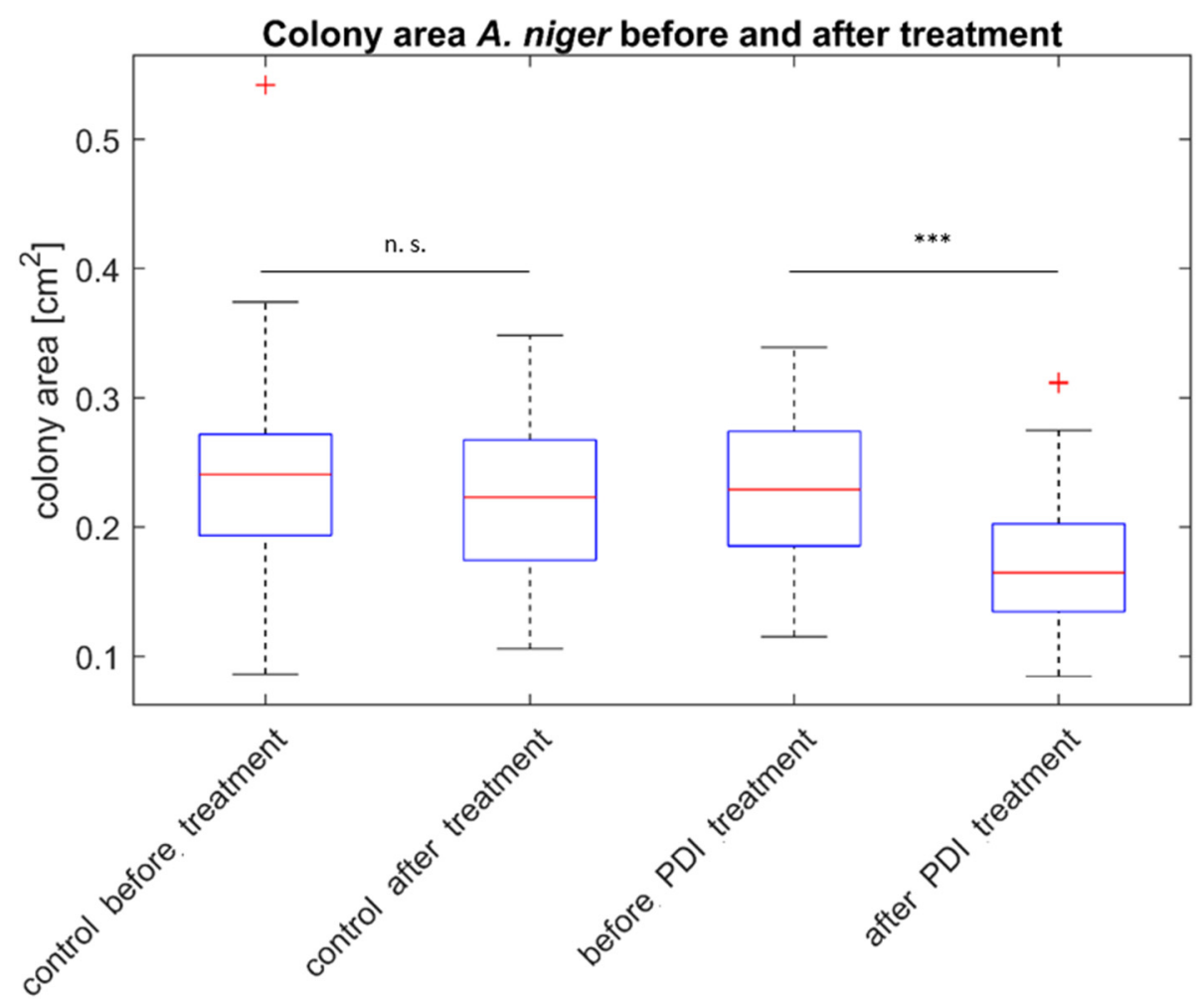

Figure 4. Colony area of mycelial patches of $A$. niger before and after treatment. The plot shows the median and the standard deviation of the colony area. Statistical significance of the area before and after treatment is indicated with no significance (n. s.), $\left.p<0.001{ }^{* * *}\right) . n_{\text {control }}=33, n_{\text {treatment }}=60$.

After incubating the samples at growth conditions for $48 \mathrm{~h}$ post-treatment it can be seen that the control sample developed black spores, while the development slows down in the samples treated with $100 \mu \mathrm{M}$ SA-CUR12a and after $48 \mathrm{~h}$ there are fewer or no spores (Figure 5). In colonies treated with $100 \mu \mathrm{M}$ curcumin $+0.5 \% \mathrm{DMSO}$, growth was completely inhibited and no new mycelium was formed.

Looking at the growth of the colonies after treatment over time, it can be seen that the control samples $\mathrm{C}-/-$ and light only show a similar growth behavior: the PS control (curcumin $+0.5 \%$ DMSO) without illumination already reduced growth rate. Using at least $50 \mu \mathrm{M}$ of curcumin with $0.5 \%$ DMSO, the growth was completely suppressed. Lower concentrations of curcumin $(10 \mu \mathrm{M}, 20 \mu \mathrm{M}+0.5 \%$ DMSO $)$ still resulted in a significant difference in the grown area after $48 \mathrm{~h}$ (Figure 6).

The cationic SA-CUR 12a did not induce any dark toxicity (Figure 7). The highest phototoxicity of SA-CUR 12a was observed at a concentration of $100 \mu \mathrm{M}$ with a mean colony area after $48 \mathrm{~h}$ of $3.0 \mathrm{~mm}^{2}$. At lower concentrations, the photoantimycotic effect was less pronounced with decreasing concentration of SA-CUR 12a. 


\section{A. niger colony $48 \mathrm{~h}$ after treatment}

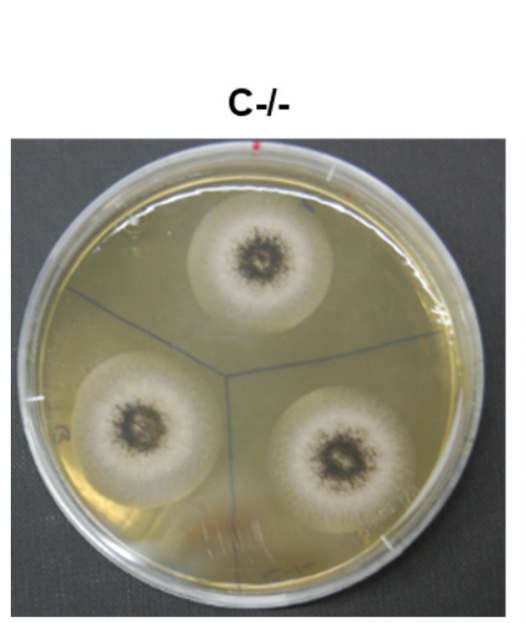

PDI

$100 \mu \mathrm{M}$ curcumin $+0.5 \%$ DMSO $100 \mu \mathrm{M}$ SA-CUR 12a
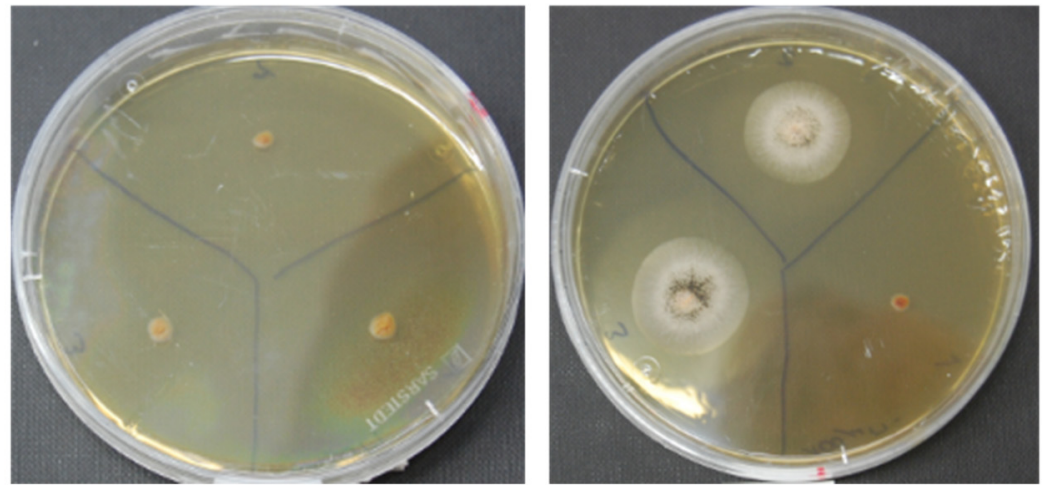

Figure 5. A. niger $48 \mathrm{~h}$ after PDI treatment. Left: control sample (C-/-), Middle: PDI treated samples with $100 \mu \mathrm{M}$ curcumin + 0.5\% DMSO, Right: PDI treated samples with $100 \mu \mathrm{M}$ SA-CUR 12a.

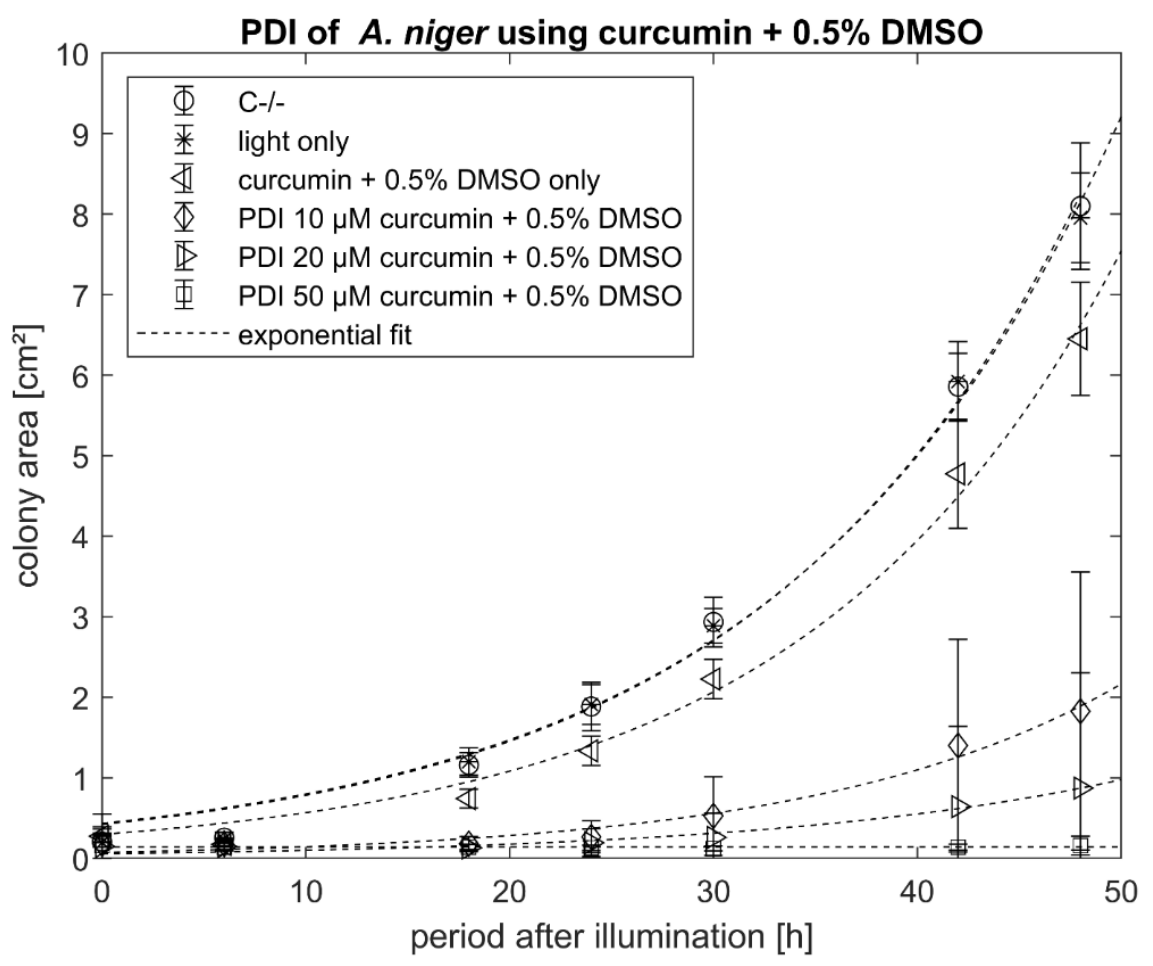

Figure 6. Phototoxicity of curcumin $+0.5 \%$ DMSO $(10 \mu \mathrm{M}, 20 \mu \mathrm{M}, 50 \mu \mathrm{M})$ against $A$. niger. The incubation period before illumination was $20 \mathrm{~min}$. Illumination was performed with $15.8 \mathrm{~J} \mathrm{~cm}-2 / 435 \mathrm{~nm}$. Plotted is the mean and standard deviation $(n=9)$. The dotted line indicates an exponential fit.

To examine whether the phototoxicity of SA-CUR 12a can be increased with DMSO, experiments with $10 \%$ of this permeability enhancer were performed. For SA-CUR 12a with $10 \%$ DMSO, the highest antimicrobial effect of SA-CUR 12a was achieved with 100 $\mu \mathrm{M}$ (mean colony area after $48 \mathrm{~h}$ of $3.4 \mathrm{~mm}^{2}$, see Figure 8 ). 


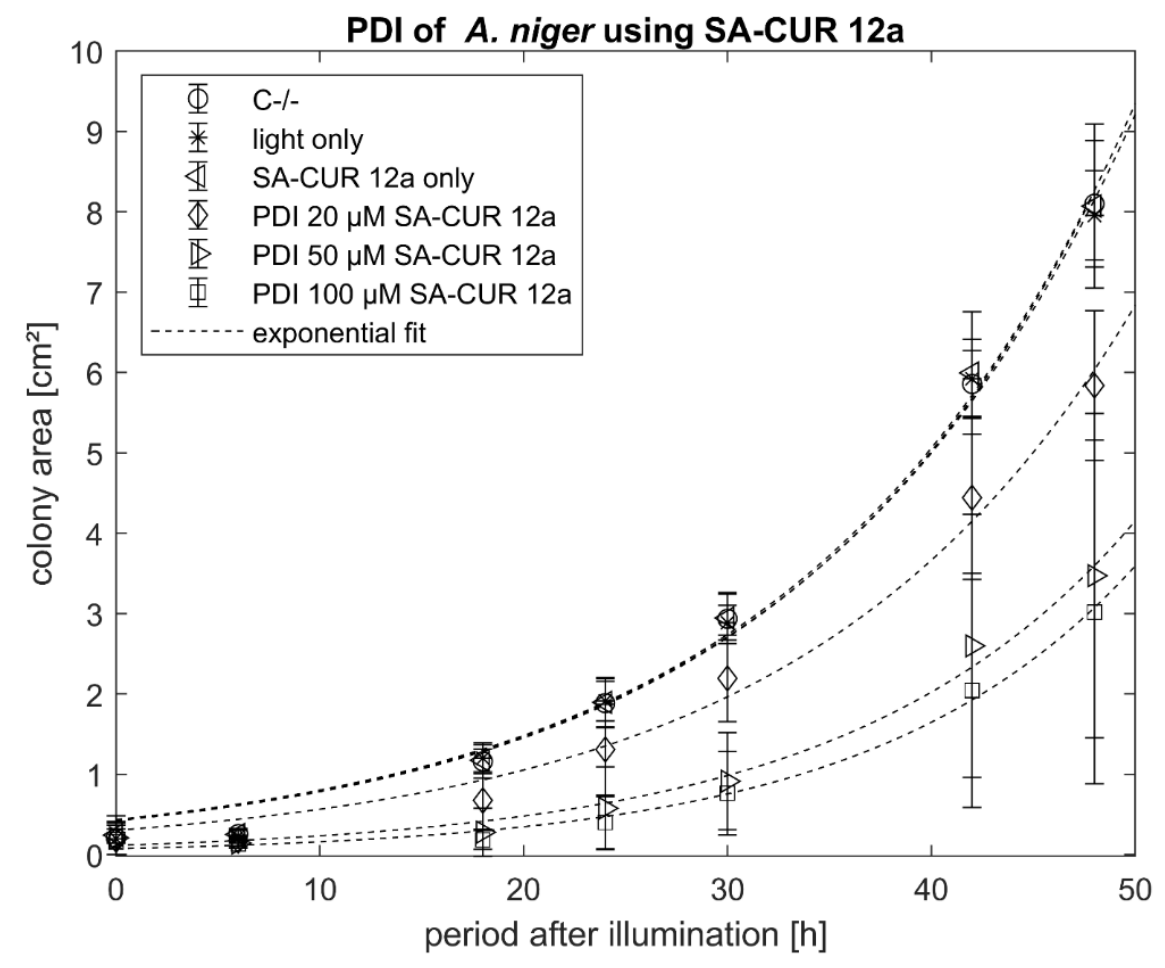

Figure 7. Phototoxicity of SA-CUR $12 \mathrm{a}(20 \mu \mathrm{M}, 50 \mu \mathrm{M}$ or $100 \mu \mathrm{M})$ against $A$. niger. The incubation period before illumination was $20 \mathrm{~min}$. Illumination was performed with $15.8 \mathrm{~J} \mathrm{~cm}-2 / 435 \mathrm{~nm}$. Plotted is the mean and standard deviation $(n=9)$. The dotted lines indicate an exponential fit.

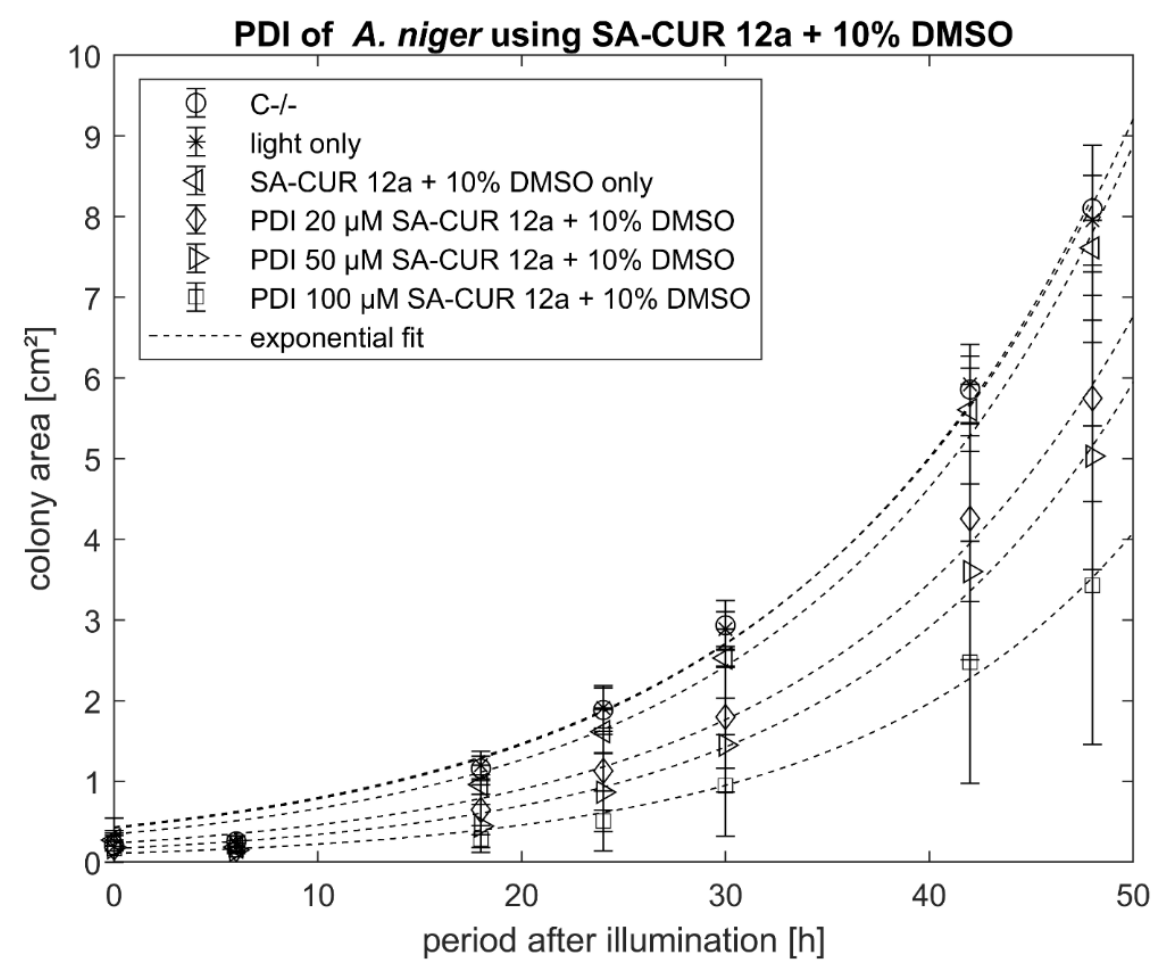

Figure 8. Phototoxicity of SA-CUR $12 \mathrm{a}+10 \%$ DMSO $(20 \mu \mathrm{M}, 50 \mu \mathrm{M}, 100 \mu \mathrm{M})$ against $A$. niger. The incubation period before illumination was $20 \mathrm{~min}$. Illumination was performed with $15.8 \mathrm{~J} \mathrm{~cm}-2 / 435 \mathrm{~nm}$. Plotted is the mean and standard deviation $(n=9)$. The dotted lines indicate an exponential fit. 
Figure 9 summarizes the colony areas of $A$. niger $48 \mathrm{~h}$ post-treatment. Curcumin in combination with DMSO induces significant $(p<0.05)$ dark toxicity. The individual treatments do all show a significant decrease in the colony area when compared to $\mathrm{C}-/-$. The lowest effect is seen with $20 \mu \mathrm{M}$ SA-CUR 12a and the highest with curcumin with $10 \%$ DMSO at the concentrations $50 \mu \mathrm{M}$ and $100 \mu \mathrm{M}$, inducing complete growth inhibition.

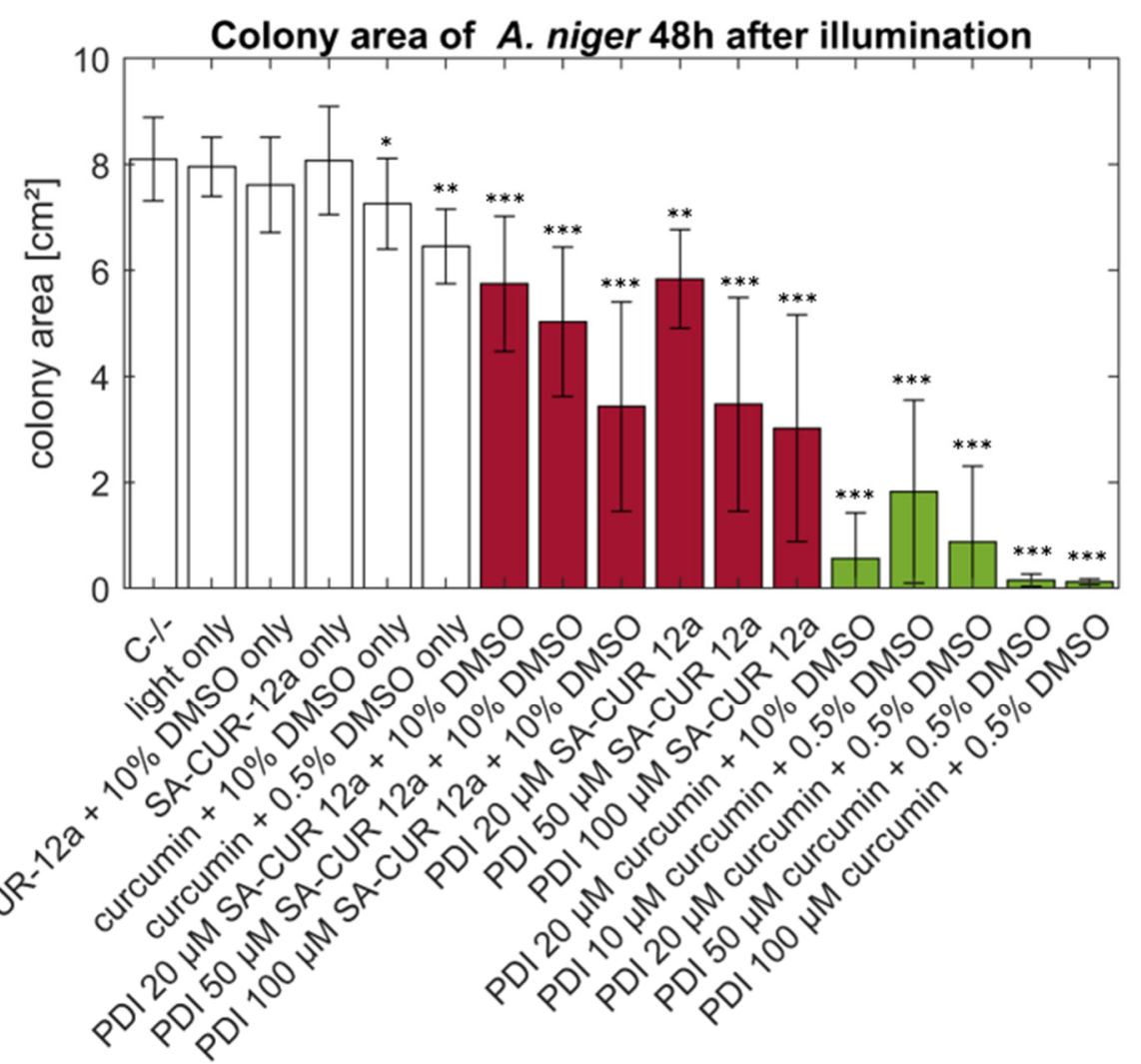

Figure 9. Summary of phototoxicity of SA-CUR-12a (red) and curcumin (green) in different concentrations and different supplementation of DMSO against $A$. niger. The incubation period before illumination was $20 \mathrm{~min}$. The plotted colony area was determined after $48 \mathrm{~h}$ post-treatment. Illumination was performed with $15.8 \mathrm{~J} \mathrm{~cm}^{-2} / 435 \mathrm{~nm}$. Plotted is the mean and standard deviation $(n=9)$. Statistical significance between individual treatments and $\mathrm{C}-/-$ was indicated with $p<0.05\left(^{*}\right)$, $p<0.005^{(* *)}, p<0.001{ }^{(* *)}$.

\section{Discussion}

Fungal infections in humans as well as fungal contamination of buildings or in food causes high costs for society [6,32]. In the medical sector, there are only a small number of substances approved for the treatment of fungal infection, with the drawback of having the potential to develop an antimicrobial resistance [5]. Indeed, the resistance of Candida against fluconazole is increasing alarmingly: Since the discovery of multidrug-resistant Candida spp. C. auris in Japan, outbreaks were detected in hospitals in several countries around the globe [33]. The majority ( $>90 \%)$ of C. auris isolates are resistant to fluconazole, an anti-fungal drug widely used in hospitals [17]. This is of particular concern as the availability of approved antifungal treatments is very limited [5].

In the case of fungal infestation, e.g., mold in buildings, some of the agents used are harmful to the inhabitants [22]. Conventional chemical disinfectants to combat fungi often contain bleach, which is a highly reactive substance, or ethanol, which is easily flammable. While bleach is effective against fungi, it also poses a health risk to the user as it can irritate the skin and respiratory tract. Therefore the use of these two substances should therefore be restricted to ventilated rooms [34]. Due to the aforementioned disadvantages 
of conventional antifungal agents, this study focuses on the use of PDI against two fungal species with different growth behavior.

PDI using curcumin or curcumin formulations was previously proven to be highly efficient against bacteria $[24,26]$. In addition, PDI also has the potential to be used against other microbial targets, such as viruses, parasites or even fungi [8]. Due to their relevance in many aspects, more and more research is looking into the potential of PDI to combat fungi [28,35-38]. Therefore, we have shown here that PDI using curcumin and a water-soluble derivate of curcumin (SA-CUR 12a) shows potential as an alternative to conventional treatment.

To demonstrate the potential of the photoantifungal approach for clinical application, C. albicans was used as a model organism. Although $50 \mu \mathrm{M}$ curcumin with $10 \%$ DMSO (i.p. $0^{\prime}$ ) showed an antimicrobial effect of 4.7 log steps, the efficiency is lower when compared to the phototoxicity reported by Dovigo and coworkers [28]. In this study, the authors showed complete eradication $(\sim 6 \mathrm{log})$ of $C$. albicans using lower curcumin concentrations ( $20 \mu \mathrm{M}$ curcumin $+10 \%$ DMSO, i.p. $20 \mathrm{~min}$ ) and comparable light conditions (different light fluences from $5.28-26.4 \mathrm{~J} \mathrm{~cm}^{-2}$, compared to $15.8 \mathrm{~J} \mathrm{~cm}^{-2}$ in the current study). For comparison, in our study, no antimicrobial effect was observed at $20 \mu \mathrm{M}$ curcumin $+10 \%$ DMSO (i.p. 0, 5 or $25 \mathrm{~min}$, see Figure 2). Interestingly, shorter incubation periods result in more pronounced photokilling of fungi, indicative of the limited stability of curcumin in aqueous solution influencing the photoantifungal effect.

By reducing the DMSO content to a final concentration of $0.5 \%$ (50 $\mu \mathrm{M}$ curcumin $+0.5 \% \mathrm{DMSO}$, i.p. $\left.0^{\prime}\right)$ the relative inactivation was in the same order of magnitude $(>4 \log )$. Again, the phototoxic effect decreased with increasing incubation period before illumination. Reducing the concentration of DMSO in PDI using curcumin could prove beneficial, as DMSO has a broad spectrum of effects (e.g., anti-inflammatory or ROS scavenger) which could counteract photo treatment $[39,40]$. Therefore, the influence of DMSO needs to be considered when applying the method in medicinal applications. In particular, DMSO could scavenge ROS generated by PDI.

When using the water-soluble curcumin derivate SA-CUR 12a as a photosensitizer, the supplementation of DMSO becomes obsolete. The photofungal effect against $C$. albicans ( $50 \mu \mathrm{M}$ SA-CUR 12a, i.p. 0 or $5 \mathrm{~min}$ ) was in the same order of magnitude $(<4 \log )$ as for curcumin. When the concentration of SA-CUR 12a was further increased to $100 \mu \mathrm{M}$ (i.p. 5 or $25 \mathrm{~min}$ ), maximal relative inactivation ( $>6 \log$ steps) was induced.

Given the high photokilling efficiency of curcumin and SA-CUR 12a, PDI using these two substances is a promising alternative for the treatment of $C$. albicans infections. The use of curcumin in PDI against oral candidiasis has already been tested in immunosuppressed mice showing promising results ( 4 log reduction with treatment using $80 \mu \mathrm{M}$ curcumin $+10 \%$ DMSO, $37.5 \mathrm{~J} \mathrm{~cm}^{-2}$ ) [41]. Additionally, first tests were performed on the clinical application of PDI for the treatment of oral candidiasis [37] using methylene blue as a photoactive compound. This approach induced a reduction of $1.99 \log$ CFU of Candida spp. (mainly C. tropicalis and C. glabrata) after treatment of oral candidiasis in mechanically ventilated patients.

To provide insight into the potential of antifungal PDI in an environmental application, the model organism $A$. niger was used. This fungal species is also very interesting for comparison to Candida, as the experimental approach for determination of the photoantimicrobial effect is very different: viable spheres of $A$. niger with a diameter of $5 \mathrm{~mm}$, thus representing tissue-like structures with the need for the diffusion of the photoactive compound into the mycelial patches, where exposed to curcumin or SA-CUR 12a at different concentration for $20 \mathrm{~min}$ and subsequently illuminated with light $\left(15.8 \mathrm{~J} \mathrm{~cm}^{-2}\right)$. The growth of colonies was monitored for $48 \mathrm{~h}$. It was found that the treatment resulted in a significant decrease in colony size after illumination compared to the control samples. Fungal patches showing no increase in size were considered dead.

SA-CUR 12a was tested in three different concentrations $(20,50,100 \mu \mathrm{M})$. To assess the influence of DMSO on the penetration of the PD into the spheres, experiments with 
or without $10 \%$ DMSO were performed. All combinations reduced the size of mycelial patches of $A$. niger after $48 \mathrm{~h}$ but did not completely inhibit the growth of the fungus. On the contrary, using curcumin as a PS increased the antifungal effect with a total growth inhibition using concentrations of $50 \mu \mathrm{M}$ or $100 \mu \mathrm{M}$, both supplemented with $0.5 \%$ DMSO. Curcumin was found to show significant dark toxicity at $20 \mu \mathrm{M}+10 \%$ DMSO $(p<0.05)$ or $100 \mu \mathrm{M}+0.5 \%$ DMSO $(p<0.005)$.

Figure 5 shows that in untreated controls the typical Aspergillus black conidia are formed after incubation on agar plates after $48 \mathrm{~h}$. In contrast, if patches are treated with $100 \mu \mathrm{M} \mathrm{SA}-\mathrm{CUR} 12 \mathrm{a}$ the growth rate is slowed down and fewer or no conidia are formed. If $100 \mu \mathrm{M}$ curcumin $+0.5 \% \mathrm{DMSO}$ is used as a photoactive agent, there is no growth of mycelia and no conidia formation.

PDI has already been used to treat $A$. niger in previous studies; the PS used were synthetic substances (charged corrosoles and conjugated polymers) which, in contrast to the viable colonies presented here, were used to treat conidia [35,36]. Growth inhibition was observed when at least $5 \mu \mathrm{M} \mathrm{PTP} \mathrm{(polythiophene-porphyrin)} \mathrm{and} \mathrm{the} \mathrm{illumination} \mathrm{of}$ $50 \mathrm{~J} \mathrm{~cm}^{-2}$ were used. The viability of $A$. niger was reduced to $15 \%$ with $20 \mu \mathrm{M}$ PTP [36]. PDI with two different cationic corrosoles at much higher concentrations when compared to our study ( $1 \mathrm{mM}$ PS incubated for three days with constant illumination of $9 \mathrm{~mW} \mathrm{~cm}^{-2}$ ) resulted in a complete growth arrest [35]. The use of curcumin could however prove to work as a very mild, cheap, biocompatible and eco-friendly alternative to synthetic photosensitizers.

Taking the presented work and the work from literature together, PDI should be considered as a novel strategy against fungal contamination in an environmental context but also in the food industry, as curcumin is approved as a food additive E100.

\section{Conclusions}

In conclusion, the results of using the novel PS SACUR-12a and natural curcumin in PDI treatment show multiple applications in clinical and industrial settings. As C. albicans and $A$. niger are culprits for several health problems in humans and the current treatment is expensive and leads to problems such as antimicrobial resistance or pulmonary diseases, the use of PDI seems to be a promising alternative.

\section{Materials and Methods}

\subsection{Preparation of PS Solutions}

The stock solution $(100 \mathrm{mM}$ ) of curcumin (Carl Roth, Karlsruhe, $>90.6 \%$ ) was prepared by dissolving in DMSO (Fluka Analytical, Buchs, Switzerland). SACUR-12a [42] was kindly provided by Dr. Andreas Spaeth (Institute of Organic Chemistry, University of Regensburg, Regensburg, Germany). A stock solution ( $5 \mathrm{mM}$ ) of SACUR-12a was prepared in $\mathrm{ddH}_{2} \mathrm{O}$. Both stock solutions were stored at $-20^{\circ} \mathrm{C}$ in the dark until use. The chemical structures of curcumin and SA-CUR 12a [42] are shown in Figure 10.

\subsection{Culture of C. albicans}

Candida albicans (Mya 273, ATCC) was grown in $20 \mathrm{~mL}$ Sabouraud Broth (SB) media containing $32 \mathrm{~g} \mathrm{~L}^{-1}$ peptone from casein tryptic digested (Carl Roth), $20 \mathrm{~g} \mathrm{~L}^{-1}$ yeast extract (AppliChem, Darmstadt, Germany), $5 \mathrm{~g} \mathrm{~L}^{-1}$ sodium chloride (VWR, PA, USA), and $5 \mathrm{mM}$ sodium hydroxide (Fluka Analytical, Buchs, Switzerland) overnight at $37^{\circ} \mathrm{C}$ under constant agitation (200 rpm).

\subsection{PDI against $C$. albicans}

The overnight culture was diluted with SB media to absorption of $0.05 \mathrm{AU}$ at $600 \mathrm{~nm}$ (Infinite M200, Tecan, Switzerland) and incubated for $4 \mathrm{~h}$ at $37^{\circ} \mathrm{C}$ and $200 \mathrm{rpm}$ to a final concentration of about $0.3 \mathrm{AU}$ at $600 \mathrm{~nm}$ (corresponding to about $6.5 \log \mathrm{CFU}$ per $2 \mathrm{~mL}$ culture). For each treatment, $2 \mathrm{~mL}$ of the cultures were centrifuged at $830 \mathrm{rcf}$ for $3 \mathrm{~min}$ (Centrifuge 5417R, Eppendorf, Hamburg, Germany). The supernatant was removed and the pellet was resuspended in $1 \mathrm{~mL}$ sterile filtered DPBS (Dulbecco's Phosphate Buffered 
Saline, Lonza Group, Verviers, Belgium) containing the different concentrations of the photosensitizer $(10 \mu \mathrm{M}, 50 \mu \mathrm{M}$ or $100 \mu \mathrm{M}$ SACUR-12a; $5 \mu \mathrm{M}, 10 \mu \mathrm{M}, 20 \mu \mathrm{M}$ or $50 \mu \mathrm{M}$ curcumin with $0.5 \%$ or $10 \%$ DMSO). Three controls were used for each experiment: $\mathrm{C}-/-$ (without PS and illumination), PS only (with PS at the highest concentration used in the experiment and no light), and light only (no PS, but with illumination). The samples were then incubated in the dark for different periods of time ( 0,5 or $25 \mathrm{~min})$. All control samples were incubated for $25 \mathrm{~min}$. Subsequently, the samples and the light control were illuminated from below with a self-made LED array $\left(435 \mathrm{~nm}, 15.8 \mathrm{~J} \mathrm{~cm}^{-2}\right)$ under constant shaking (400 rpm) for $1 \mathrm{~h}$. The C-/ - and PS-only control were incubated under constant shaking (400 rpm) in the dark for $1 \mathrm{~h}$. The samples were serially diluted in DPBS and plated on SB plates containing 1.5\% Agar-Agar Kobe I (Carl Roth) and incubated for one day at $37^{\circ} \mathrm{C}$ followed by counting the colony-forming unit (CFU). All experiments were repeated three times.<smiles>[NH3+]CCOc1ccc(/C=C/C(=O)CC(=O)/C=C/c2ccc(OCC[NH3+])c3ccccc23)c2ccccc12</smiles><smiles>COc1cc(/C=C/C(=O)CC(=O)/C=C/c2ccc(O)c(OC)c2)ccc1O</smiles>

Figure 10. Chemical structures of SA-CUR 12 a (top) and curcumin (bottom).

\subsection{Culture of A. niger}

Conidida from clinical isolates of Aspergillus niger, kindly provided by PD Dr. Tim Maisch (University Regensburg), were harvested using a sterile inoculation loop. The conidia were transferred to $20 \mathrm{~mL}$ SB media containing $0.2 \mathrm{mM}$ Tween-20 (Carl Roth $\mathrm{GmbH}+\mathrm{CoKg}$ ) and incubated for two days at $37^{\circ} \mathrm{C}$ in a $50 \mathrm{~mL}$ Greiner tube with constant shaking (200 rpm) (method adapted from [43]). A total of $1 \mathrm{~mL}$ of the liquid culture was used to inoculate $30 \mathrm{~mL}$ of fresh SB media. This subculture was incubated for two days at $37^{\circ} \mathrm{C}$ in a $50 \mathrm{~mL}$ Greiner tube with constant shaking ( $200 \mathrm{rpm}$ ) before being used for PDI.

\subsection{PDI against A. niger}

Single colonies (sphere diameter: $5 \mathrm{~mm}$ ) of $A$. niger were transferred to $500 \mu \mathrm{L}$ of treatment solutions containing different concentrations of PS diluted in DBPS. Three controls were used for each experiment: C-/- (without a PS and illumination), PS control (with PS in the highest concentration used in the experiment and no light) and light control (illumination with the samples but without a PS). The samples were then incubated for $20 \mathrm{~min}$ in the dark at room temperature with constant shaking (400 rpm). Afterward, the samples, except for $\mathrm{C}-/$ - and PS control, were illuminated with an LED array $\left(435 \mathrm{~nm}, 15.8 \mathrm{~J} \mathrm{~cm}^{-2}\right)$ from below under constant shaking (400 rpm). The $\mathrm{C}-/-$ and the PS control were incubated under constant shaking in the dark for one hour using the same shaker as the samples. The colonies were then transferred to an SB agar 
plate containing 1.5\% Agar-Agar Kobe I (for microbiology, Carl Roth $\mathrm{GmbH}+\mathrm{CoKg}$ ) and incubated for three days at $37^{\circ} \mathrm{C}$ (adapted from [43]).

Growth inhibition was investigated by imaging the cultures at different time points and measuring the colony area using the image processing and analyzing software ImageJ 1.48v (National Institute of Health, Bethesda, MD, USA [44]). Each experiment was reproduced nine times.

\subsection{Data Analysis}

Unless otherwise stated, data represent the mean with the corresponding error bars of standard deviation of the relative inactivation $(C$. albicans, $n=3)$ or the colony area (A. niger, $n=9$ ). The relative inactivation was calculated by dividing the CFU of the corresponding $\mathrm{C}-/-$ by the CFU of the individual treatments. In the case of complete inactivation $(\mathrm{CFU}=0)$ the $\mathrm{CFU}$ of the $\mathrm{C}-/-$ was divided by one [29]. The dashed line in the $C$. albicans plots represents a $3 \log$ reduction, which marks the minimum reduction for an antimicrobial effect. Data analysis was performed using Excel (v2016, Microsoft, Redmond, WA, USA) and Matlab R2019a (MathWorks, Natick, MA, USA). Statistical analysis was performed using RStudio version 1.4 (Bosten, MA, USA) using the Mann-Whitney U test. Statistical significance was indicated with $p<0.05\left(^{(*)}, p<0.005\left(^{* *}\right), p<0.001\left(^{(* *)}\right.\right.$.

Author Contributions: Conceptualization, K.P.; project administration, K.P.; supervision, K.P.; resources, K.P.; investigation, B.S.; data analysis, B.S.; visualization, B.S.; writing-original draft preparation, B.S.; writing - review \& editing, B.S. and K.P. All authors have read and agreed to the published version of the manuscript.

Funding: This research received no external funding.

Data Availability Statement: The data presented in this study are available within this article.

Acknowledgments: The authors are grateful to Andreas Spaeth, University of Regensburg for providing SA-CUR 12a and to Tim Maisch, University Medical Center Regensburg for providing A. niger. Further thanks go to Michael Glueck and Nicole Tortik for their support in the laboratory. We thank John W. C. Dunlop, Paris Lodron University of Salzburg for proofreading.

Conflicts of Interest: The authors declare no conflict of interest.

$\begin{array}{ll}\text { Abbreviations } \\ \text { A. niger } & \text { Aspergillus niger } \\ \text { C. albicans } & \text { Candida albicans } \\ \text { CFU } & \text { Colony forming unit(s) } \\ \text { DPBS } & \text { Dulbecco's Phosphate Buffered Saline } \\ \text { i.p. } & \text { incubation period } \\ \text { PDI } & \text { Photodynamic Inactivation } \\ \text { PS } & \text { Photosensitiser } \\ \text { ROS } & \text { Reactive oxygen species } \\ \text { SB } & \text { Sabouraud Broth }\end{array}$

\section{Appendix A}

Values represented in Figure 4 are including the following samples:

\begin{tabular}{|c|c|}
\hline Control before and after Illumination & Treatment before and after Illumination \\
\hline$C-/-[n=6]$ & PDI $10 \mu \mathrm{M}$ curcumin $+0.5 \%$ DMSO $[n=9]$ \\
\hline Light only $[n=6]$ & PDI $20 \mu \mathrm{M}$ curcumin $+0.5 \%$ DMSO $[n=6]$ \\
\hline Curcumin $+0.5 \%$ DMSO only $[n=9]$ & PDI $50 \mu \mathrm{M}$ curcumin $+0.5 \%$ DMSO $[n=9]$ \\
\hline SA-CUR 12 a only $[n=6]$ & PDI $20 \mu \mathrm{M}$ SA-CUR 12a [ $n=6]$ \\
\hline \multirow[t]{5}{*}{ SA-CUR $12 \mathrm{a}+10 \%$ DMSO only $[n=6]$} & PDI $50 \mu \mathrm{M}$ SA-CUR 12a $[n=6]$ \\
\hline & PDI $100 \mu \mathrm{M}$ SA-CUR 12a $[n=6]$ \\
\hline & PDI $20 \mu$ M SA-CUR 12a + 10\% DMSO [ $n=6]$ \\
\hline & PDI $50 \mu \mathrm{M}$ SA-CUR $12 \mathrm{a}+10 \%$ DMSO $[n=6]$ \\
\hline & PDI $100 \mu$ M SA-CUR $12 \mathrm{a}+10 \%$ DMSO $[n=6]$ \\
\hline
\end{tabular}




\section{References}

1. Mayer, F.L.; Wilson, D.; Hube, B. Candida albicans pathogenicity mechanisms. Virulence 2013, 4, 119-128. [CrossRef]

2. Richardson, M.; Lass-Flörl, C. Changing epidemiology of systemic fungal infections. Clin. Microbiol. Infect. 2008, 14, 5-24. [CrossRef]

3. Lockhart, S.R.; Guarner, J. Emerging and reemerging fungal infections. Semin. Diagn. Pathol. 2019, 36, 177-181. [CrossRef]

4. Friedman, D.Z.P.; Schwartz, I.S. Emerging Fungal Infections: New Patients, New Patterns, and New Pathogens. J. Fungi 2019, 5, 67. [CrossRef]

5. Pianalto, K.M.; Alspaugh, J.A. New Horizons in Antifungal Therapy. J. Fungi 2016, 2, 26. [CrossRef]

6. Awada, M.; Becerik-Gerber, B.; Hoque, S.; O'Neill, Z.; Pedrielli, G.; Wen, J.; Wu, T. Ten questions concerning occupant health in buildings during normal operations and extreme events including the COVID-19 pandemic. Build. Environ. 2021, 188, 107480. [CrossRef]

7. Dai, T.; Huang, Y.-Y.; Hamblin, M.R. Photodynamic therapy for localized infections-State of the art. Photodiagnosis Photodyn. Ther. 2009, 6, 170-188. [CrossRef]

8. $\quad$ Sperandio, F.F.; Huang, Y.-Y.; Hamblin, M.R. Antimicrobial photodynamic therapy to kill Gram-negative bacteria. Recent Pat. Anti Infect. Drug Discov. 2013, 8, 108-120. [CrossRef]

9. Jori, G. Photodynamic Therapy of Microbial Infections: State of the Art and Perspectives. J. Environ. Pathol. Toxicol. Oncol. 2006, 25, 505-520. [CrossRef]

10. Kharkwal, G.B.; Sharma, S.K.; Huang, Y.-Y.; Dai, T.; Hamblin, M.R. Photodynamic therapy for infections: Clinical applications. Lasers Surg. Med. 2011, 43, 755-767. [CrossRef]

11. Zheng, D.; Huang, C.; Huang, H.; Zhao, Y.; Khan, M.R.U.; Zhao, H.; Huang, L. Antibacterial Mechanism of Curcumin: A Review. Chem. Biodivers. 2020, 17, e2000171. [CrossRef] [PubMed]

12. Picco, D.d.C.R.; Cavalcante, L.L.R.; Trevisan, R.L.B.; Souza-Gabriel, A.E.; Borsatto, M.C.; Corona, S.A.M. Effect of curcuminmediated photodynamic therapy on Streptococcus mutans and Candida albicans: A systematic review of in vitro studies. Photodiagnosis Photodyn. Ther. 2019, 27, 455-461. [CrossRef]

13. Hamblin, M.R. Antimicrobial photodynamic inactivation: A bright new technique to kill resistant microbes. Curr. Opin. Microbiol. 2016, 33, 67-73. [CrossRef] [PubMed]

14. Maisch, T. Resistance in antimicrobial photodynamic inactivation of bacteria. Photochem. Photobiol. Sci. 2015, 14, 1518-1526. [CrossRef]

15. Kashef, N.; Hamblin, M.R. Can microbial cells develop resistance to oxidative stress in antimicrobial photodynamic inactivation? Drug Resist. Updates 2017, 31, 31-42. [CrossRef]

16. Toda, M.; Williams, S.R.; Berkow, E.L.; Farley, M.M.; Harrison, L.H.; Bonner, L.; Marceaux, K.M.; Hollick, R.; Zhang, A.Y.; Schaffner, W.; et al. Population-Based Active Surveillance for Culture-Confirmed Candidemia-Four Sites, United States, 2012-2016. MMWR Surveill Summ. 2019, 68, 1-15. [CrossRef]

17. Lockhart, S.R.; Etienne, K.A.; Vallabhaneni, S.; Farooqi, J.; Chowdhary, A.; Govender, N.P.; Colombo, A.L.; Calvo, B.; Cuomo, C.A.; Desjardins, C.A.; et al. Simultaneous Emergence of Multidrug-Resistant Candida auris on 3 Continents Confirmed by Whole-Genome Sequencing and Epidemiological Analyses. Clin. Infect. Dis. 2016, 64, 134-140. [CrossRef]

18. Grimm, L.H.; Kelly, S.; Krull, R.; Hempel, D.C. Morphology and productivity of filamentous fungi. Appl. Microbiol. Biotechnol. 2005, 69, 375-384. [CrossRef]

19. Jenks, J.D.; Hoenigl, M. Treatment of Aspergillosis. J. Fungi 2018, 4, 98. [CrossRef]

20. Brambilla, A.; Sangiorgio, A. Mould growth in energy efficient buildings: Causes, health implications and strategies to mitigate the risk. Renew. Sustain. Energy Rev. 2020, 132, 110093. [CrossRef]

21. Klepeis, N.E.; Nelson, W.C.; Ott, W.R.; Robinson, J.P.; Tsang, A.M.; Switzer, P.; Behar, J.V.; Hern, S.C.; Engelmann, W.H. The National Human Activity Pattern Survey (NHAPS): A resource for assessing exposure to environmental pollutants. J. Expo. Sci. Environ. Epidemiol. 2001, 11, 231-252. [CrossRef]

22. U.S. Environmental Protection Agency Indoor Environments Devision. Mold Remediation in Schools and Commercial Buildings. EPA 402-K-01-001; U.S. EPA, 2008. Available online: https: / / www.epa.gov/mold/printable-version-mold-remediation-schoolsand-commercial-buildings (accessed on 21 October 2021).

23. CDC. Antibiotic Resistance Threats in the United States, 2019; US Department of Health and Human Services, Centres for Disease Control Prevention: Atlanta, GA, USA, 2019. [CrossRef]

24. Winter, S.; Tortik, N.; Kubin, A.; Krammer, B.; Plaetzer, K. Back to the roots: Photodynamic inactivation of bacteria based on water-soluble curcumin bound to polyvinylpyrrolidone as a photosensitizer. Photochem. Photobiol. Sci. 2013, 12, 1795-1802. [CrossRef]

25. Chignell, C.F.; Bilskj, P.; Reszka, K.J.; Motten, A.G.; Sik, R.H.; Dahl, T.A. Spectral and photochemical properties of curcumin. Photochem. Photobiol. 1994, 59, 295-302. [CrossRef]

26. Ribeiro, A.P.; Pavarina, A.C.; Dovigo, L.N.; Brunetti, I.L.; Bagnato, V.S.; Vergani, C.E.; Costa, C.A. Phototoxic effect of curcumin on methicillin-resistant Staphylococcus aureus and L929 fibroblasts. Lasers Med. Sci. 2013, 28, 391-398. [CrossRef]

27. Al-Asmari, F.; Mereddy, R.; Sultanbawa, Y. A novel photosensitization treatment for the inactivation of fungal spores and cells mediated by curcumin. J. Photochem. Photobiol. B Biol. 2017, 173, 301-306. [CrossRef] 
28. Dovigo, L.N.; Pavarina, A.C.; Ribeiro, A.P.; Brunetti, I.L.; Costa, C.A.; Jacomassi, D.P.; Bagnato, V.S.; Kurachi, C. Investigation of the photodynamic effects of curcumin against Candida albicans. Photochem. Photobiol. 2011, 87, 895-903. [CrossRef]

29. Glueck, M.; Schamberger, B.; Eckl, P.; Plaetzer, K.J.P.; Sciences, P. New horizons in microbiological food safety: Photodynamic Decontamination based on a curcumin derivative. Photochem. Photobiol. Sci. 2017, 16, 1784-1791. [CrossRef]

30. Spaeth, A.; Graeler, A.; Maisch, T.; Plaetzer, K. CureCuma-cationic curcuminoids with improved properties and enhanced antimicrobial photodynamic activity. Eur. J. Med. Chem. 2018, 159, 423-440. [CrossRef]

31. Tortik, N.; Steinbacher, P.; Maisch, T.; Spaeth, A.; Plaetzer, K. A comparative study on the antibacterial photodynamic efficiency of a curcumin derivative and a formulation on a porcine skin model. Photochem. Photobiol. Sci. 2016, 15, 187-195. [CrossRef]

32. Jeong, R.-D.; Shin, E.-J.; Chu, E.-H.; Park, H.-J. Effects of Ionizing Radiation on Postharvest Fungal Pathogens. Plant Pathol. J. 2015, 31, 176-180. [CrossRef]

33. Jeffery-Smith, A.; Taori, S.K.; Schelenz, S.; Jeffery, K.; Johnson, E.M.; Borman, A.; Manuel, R.; Brown, C.S. Candida auris: A Review of the Literature. Clin. Microbiol. Rev. 2018, 31, e00029-17. [CrossRef] [PubMed]

34. WHO. Annex, G Use of Disinfectants: Alcohol and Bleach. Infection Prevention and Control of Epidemic-and Pandemic-Prone Acute Respiratory Infections in Health Care; World Health Organization: Geneva, Switzerland, 2014; pp. 65-66.

35. Preuß, A.; Saltsman, I.; Mahammed, A.; Pfitzner, M.; Goldberg, I.; Gross, Z.; Röder, B. Photodynamic inactivation of mold fungi spores by newly developed charged corroles. J. Photochem. Photobiol. B Biol. 2014, 133, 39-46. [CrossRef]

36. Xing, C.; Yang, G.; Liu, L.; Yang, Q.; Lv, F.; Wang, S. Conjugated Polymers for Light-Activated Antifungal Activity. Small 2012, 8, 525-529. [CrossRef]

37. Alves, A.D.; Gurgel-Juarez, N.; Vieira, A.C.; Proietti, A.A.; Pinheiro Barcessat, A.R. PDT technology: An alternative to control oral candidiasis in critically ill patients. Lasers Dent. Sci. 2021, 5, 193-197. [CrossRef]

38. Martín Santiago, M.P.; Gutknecht, N.; Martín-Carrillo, N.; Foronda, P.; Valladares, B.; Montero Gómez, N. In vitro study of photodynamic therapy with visible laser systems applied to fungal infections. Lasers Dent. Sci. 2020, 4, 103-110. [CrossRef]

39. Huang, S.-H.; Wu, C.-H.; Chen, S.-J.; Sytwu, H.-K.; Lin, G.-J. Immunomodulatory effects and potential clinical applications of dimethyl sulfoxide. Immunobiology 2020, 225, 151906. [CrossRef]

40. Santos, N.C.; Figueira-Coelho, J.; Martins-Silva, J.; Saldanha, C. Multidisciplinary utilization of dimethyl sulfoxide: Pharmacological, cellular, and molecular aspects. Biochem. Pharmacol. 2003, 65, 1035-1041. [CrossRef]

41. Dovigo, L.N.; Carmello, J.C.; de Souza Costa, C.A.; Vergani, C.E.; Brunetti, I.L.; Bagnato, V.S.; Pavarina, A.C. Curcumin-mediated photodynamic inactivation of Candida albicans in a murine model of oral candidiasis. Med. Mycol. 2013, 51, 243-251. [CrossRef]

42. Spaeth, A.; Plaetzer, K.; Maisch, T.; Eichner, A. 1,7-Diaryl-1,6-Heptadien-3,5-Dion-Derivate, Verfahren zur Herstellung und Verwendung Derselben; E.P. Office: Munich, Germany, 2017.

43. Heinlin, J.; Maisch, T.; Zimmermann, J.L.; Shimizu, T.; Holzmann, T.; Simon, M.; Heider, J.; Landthaler, M.; Morfill, G.; Karrer, S. Contact-free inactivation of Trichophyton rubrum and Microsporum canis by cold atmospheric plasma treatment. Future Microbiol. 2013, 8, 1097-1106. [CrossRef]

44. NIH. ImageJ. Available online: http:/ / imagej.nih.gov/ij/ (accessed on 13 September 2015). 